\title{
Eyes in the Sky: Assessing the Feasibility of Low-Cost, Ready-to-Use Unmanned Aerial Vehicles to Monitor Primate Populations Directly
}

\author{
Brandon P. Semel $^{a} \quad$ Sarah M. Karpanty ${ }^{a}$ \\ Faramalala Francette Vololonirina ${ }^{b}$ \\ Ando Nantenaina Rakotonanahary ${ }^{c}$ \\ a Department of Fish and Wildlife Conservation, Virginia Tech, Blacksburg, VA, USA; \\ ${ }^{b}$ Department of Palaeontology and Biological Anthropology, University of Antananarivo, \\ Antananarivo, Madagascar; ${ }^{\mathrm{C}}$ Department of Primatology and Evolution, Mahajanga \\ University, Mahajanga, Madagascar
}

\section{Keywords}

Unmanned aerial vehicle · Drone · Quad-copter · Madagascar · Lemur · Sifaka ·

Abundance · Survey

\begin{abstract}
Primates face many climate and land use change threats, making long-term population monitoring critical to prioritizing conservation efforts. Ground-based line transects are typically conducted to estimate and monitor primate populations. However, transects may be costly and logistically challenging. We sought to test whether low-cost $(<5,000$ USD), ready-to-use unmanned aerial vehicles (UAVs) could effectively monitor primate populations in north-eastern Madagascar. Critically Endangered [A3cd] goldencrowned sifakas (Propithecus tattersalli) are medium-sized, white lemurs whose creamy colour contrasts against defoliated tree canopies, making them an ideal study species for aerial counts. Quad-copter UAV flights over sifaka groups did not elicit antipredator responses. Photographs demonstrated the ability of UAVs to capture viable imagery of sifakas from approximately $20 \mathrm{~m}$ above ground level. Unfortunately, crashes resulting from an inability to programme automated flights over hilly forests cut this pilot study short, highlighting several challenges that remain to implementing UAVs in remote field studies. This study demonstrates that while UAVs offer considerable promise in the future of primate research and conservation, high start-up costs and remote field conditions provide challenging obstacles to first time users hoping to use this exciting new technology. Furthermore, we strongly recommend that thermal cameras be used for direct primate counts with UAVs.

(c) 2019 S. Karger AG, Basel
\end{abstract}

\section{KARGER \\ E-Mail karger@karger.com www.karger.com/fpr}

(c) 2019 S. Karger AG, Basel
Brandon Semel

310 West Campus Dr.

Blacksburg, VA 24061 (USA)

E-Mail bsemel@vt.edu 


\section{Introduction}

Quantifying baseline population sizes and monitoring change are critical to implementing and evaluating primate conservation actions [Campbell et al., 2016]. Ground-based line transects are commonly used in primate studies to estimate population size, density and to monitor responses to threats [Peres, 1999; Buckland et al., 2010; Campbell et al., 2016]; however, the cost and logistics of ground-based transects may limit their use and reliability. Obtaining minimum sample size requirements across vast wilderness areas on foot may cost multiple thousands of dollars per year [S. Karpanty, pers. commun.; this study]. Rugged terrain in remote areas makes sampling efforts logistically challenging, if not impossible [Li et al., 2007; Matsuda et al., 2016]. Establishing permanent monitoring transects, as recommended by Buckland et al. [2010], requires large trail networks, possibly opening forests to increased exploitation [Laurance et al., 2009].

Low-cost $(<5,000$ USD), ready-to-use unmanned aerial vehicles (UAVs) have the potential to overcome these challenges, especially for multi-year monitoring efforts [Koh and Wich, 2012; Paneque-Gálvez et al., 2014]. A growing number of studies have assessed the feasibility of UAV surveys for wildlife in difficult terrains, including cliffs, forests and ocean habitats [Linchant et al., 2015; Christie et al., 2016; Schoefield et al., 2017]. Large animals, such as elephants (Loxodonta africana), have been surveyed from $>100 \mathrm{~m}$ above ground level (AGL), enabling large area sampling [Vermeulen et al., 2013]. Abundance of smaller-bodied taxa, such as geese [Anatidae; Chabot and Bird, 2012], ducks and wading birds [Anatidae, Phoenicopteridae, and Scolopacidae; Vas et al., 2015], and gulls [Larus; Grenzdorffer, 2013], has been estimated using fixed-wing and multi-rotor UAVs from 50 to $180 \mathrm{~m}$ AGL.

Few attempts to estimate primate abundance from UAVs have been published to date, and all have used indirect nest counts. Chimpanzee (Pan t. troglodytes) nest surveys found that just $8-48 \%$ of nests detected from walking surveys were also detected using UAVs and that canopy openness influences nest detectability by UAVs [van Andel et al., 2015; Bonnin et al., 2018]. Ground surveys of Sumatran orang-utan (Pongo abelii) nests found significantly more nests per kilometre than aerial surveys [Wich et al., 2016]. UAV models used in these studies (fixed-wing "Maja" and Skywalker 2013 UAVs) required some assembly and technical skills, and results suggest their utility was limited compared to ground-based nest detection rates.

Our goal was to assess the feasibility of relatively low-cost, ready-to-use UAV technology to directly survey Critically Endangered [A3cd] golden-crowned sifakas (Propithecus tattersalli; hereafter, sifakas) in deciduous forests of north-eastern Madagascar [Andriaholinirina et al., 2014]. We anticipated that the relatively large body size ( $3.5 \mathrm{~kg}, 45-47 \mathrm{~cm}$ head-body length) and white pelage of this species would distinguish individual sifakas from smaller conspecifics as well as from the defoliated tree canopies where they sleep during the dry season [Meyers, 1993; Ravosa et al., 1993; Lehman et al., 2005]. Our goals were to: (1) quantify sifaka behavioural responses to the UAV at varied test flight heights, (2) photograph sifakas from the UAV, and (3) make recommendations for more in-depth use of UAVs to monitor sifakas in deciduous forests, including a cost-benefit analysis. 


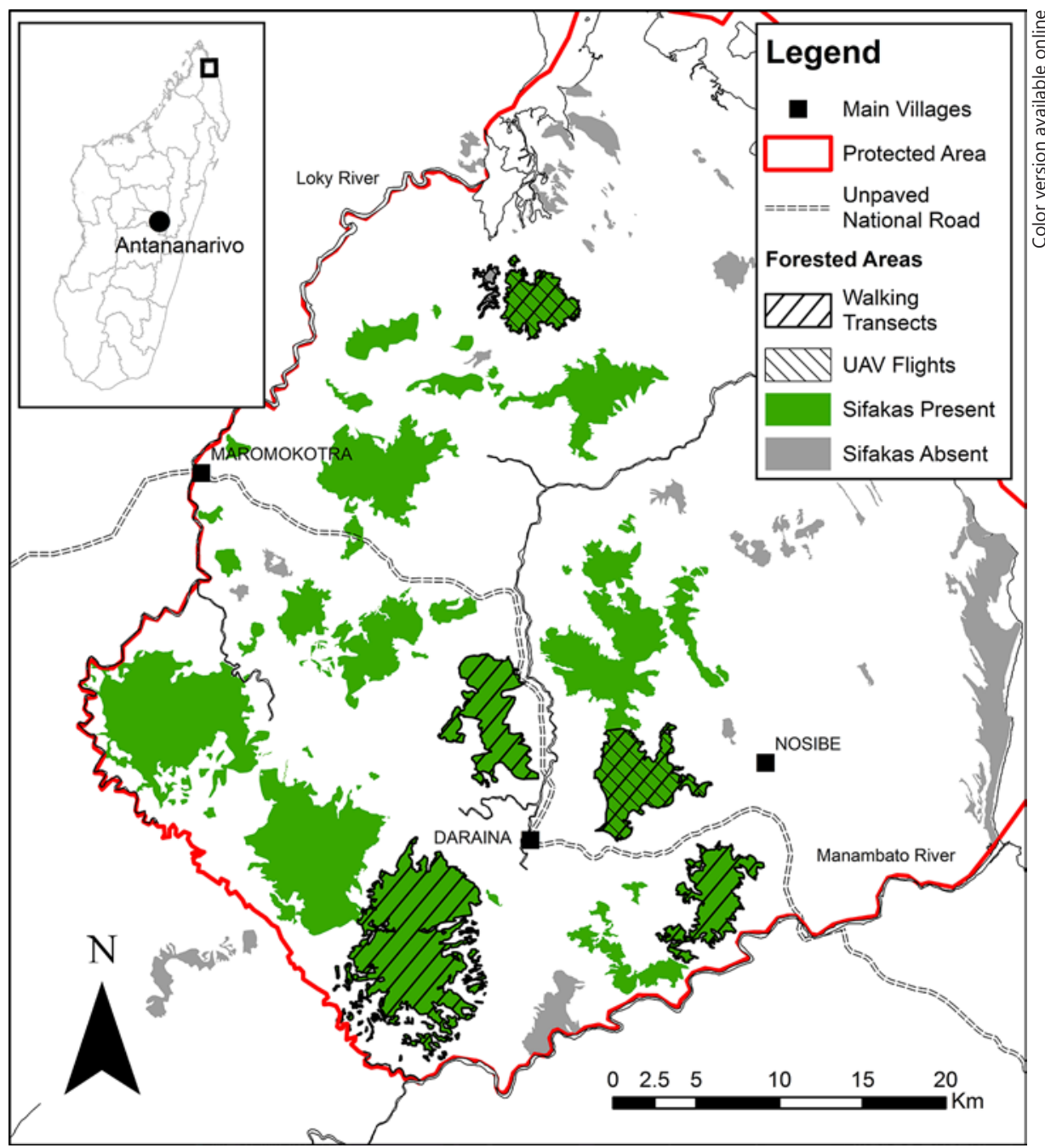

Fig. 1. Drone flights were conducted over two forest fragments in northern Madagascar's LokyManambato Protected Area.

\section{Methods}

UAV flights were conducted in north-eastern Madagascar's Daraina region $\left(49^{\circ} 56^{\prime} \mathrm{E}\right.$, $13^{\circ} 31^{\prime}$ S) from May to June 2016 (Fig. 1). The region has highly fragmented forest patches comprising dry, sclerophyllous, deciduous and dense, humid forests separated by a matrix of cattle pasture and agricultural areas [Quéméré et al., 2013]. The Loky-Manambato Protected Area encompasses seven large $\left(>23 \mathrm{~km}^{2}\right)$ and dozens of smaller fragments. It is managed by the nongovernmental organization Fanamby, for local resource extraction. UAV flights were conducted over a grassland transect interspersed with small forest fragments (Bekaraoka) and dry, deciduous sclerophyllous forests (Antsaharaingy). 


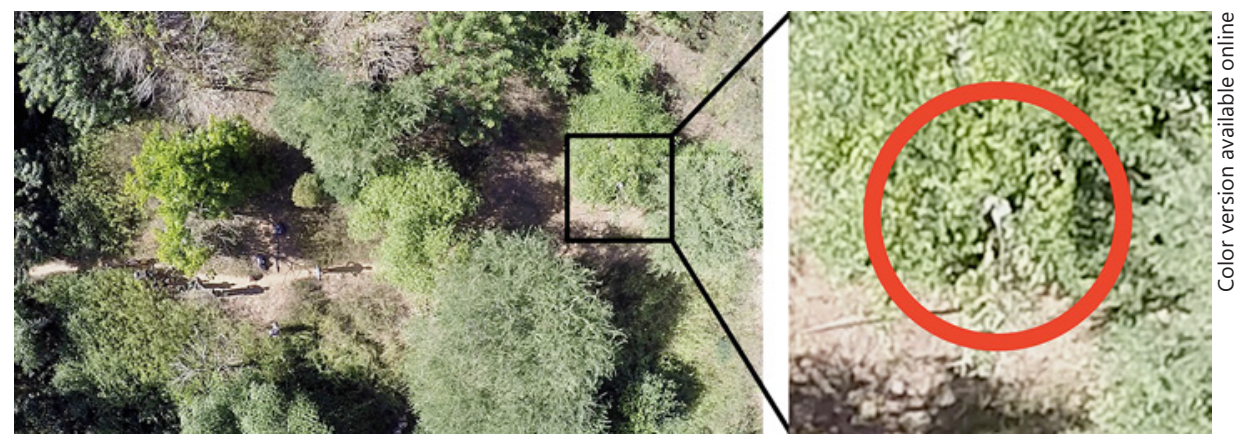

Fig. 2. A sifaka can be seen at the top of a tree (approx. $3 \mathrm{~m}$ ) in an image (screen shot from live video, $1,057 \times 422$ pixels $(72 \times 72 \mathrm{DPI}))$ taken from a Phantom II UAV flying 15-20 m AGL. Several people located on the left side of the image provide a sense of scale. The right image is an inset of the highlighted area.

We used a refurbished, ready-to-use Phantom 2 quad-copter (DJI, Shenzhen, China) fixed with a GoPro Hero4 camera (12 mega pixels; GoPro, San Mateo, CA, USA) mounted on a gimbal to optimize image quality ("refurbished" UAV estimate $<1,500$ USD including UAV, carrying case, spare parts, second battery and camera).

We first assessed the sifakas' behavioural responses to the UAV's presence. Sifakas are wary of aerial predators [Karpanty and Wright, 2007], therefore we wanted to test an elevation floor on flight heights, lest the animals flee. Flight heights were 15-55 m AGL. The UAV flew over sifakas $(5-20 \mathrm{~m} \mathrm{AGL})$ resting in both foliated $(n=2)$ and defoliated $(n=2)$ tree canopies. Test flights were conducted on four different days with 2-5 flyovers conducted each day. Continuous data collection methods were used to evaluate the response of the sifakas to the UAV [Altmann, 1974]. We recorded the number of animals present, total UAV flight time, UAV flight height and behavioural response to the UAV. Possible responses were determined a priori and included vigilance (upward gaze following the path of the UAV), alarm calling, and rapid movement away from the UAV in any direction. In the event of a response, we recorded the number of animals that responded and estimated the distance from the UAV to the first responder. UAV imagery taken above the sifakas was collected at this time as baseline imagery (Fig. 2). Images were inspected by hand to locate lemurs and stitched together using Image Composite Editor (Microsoft Corporation, Redmond, WA, USA).

UAV survey attempts were conducted on three different days. The GoPro camera took still photos based on a remote trigger or at 3- or 5-s intervals. We walked under the UAV to take GPS coordinates and UAV altitude using a handheld Garmin GPS and a Bushnell range finder every $50 \mathrm{~m}$ (the Phantom 2 did not support autopilot software or image geo-referencing). Live video feed was relayed to a screen on the controller, which also displayed the UAV's altitude and flight distance relative to the launch point. Video was not recorded due to permit restrictions, though screenshots were captured from live video. All UAV components (DJI lithium-polymer Smart Batteries, flight controller, viewing screen, GoPro camera, and laptop for image inspection) were charged in the field using a Yeti 400 Portable Power Station and two Boulder 30 solar panels $(<1,300$ USD; Goal Zero, Bluffdale, UT, USA).

Line transects ( $n=16,1-2.2 \mathrm{~km}$ long) were conducted to best estimate time and labour costs to develop a cost-benefit analysis for the two survey methods in the same study system and to compare encounter rates between UAV flights and walking transects. Two 2-member teams walked transects each morning (06:00-08:30 h) and afternoon (15:00-17:30 h). One member was rotated daily to avoid observational bias and to ensure familiarity with the transect [Buckland et al., 2010]. Survey costs were determined on a per kilometre basis for comparison. We assumed that a research university would already have a license for object-based imagery analysis software 
(e.g., eCognition) to automate animal counts from images and therefore excluded this additional cost from the analysis. Here we report only encounter rates.

This research complied with protocols approved by the Virginia Tech Institutional Animal Care and Use Committee (IACUC No. 15-223) and adhered to the legal requirements for research conducted in Madagascar (Permit No. 117/16/MEEF/SG/DGF/DAPT/SCBT).

\section{Results}

Sifakas had varied responses to the four test UAV flights to assess behavioural responses. One foliated canopy-resting group moved approximately $1 \mathrm{~m}$ higher in the tree and exhibited upward vigilance to investigate the noise each time the UAV flew 5-15 m overhead. Two other defoliated canopy-resting groups remained stationary while exhibiting upward vigilance as the UAV flew 10-20 m overhead. Only one solitary sifaka (feeding approx. $3 \mathrm{~m}$ high in a foliated tree on the edge of old growth forest) dropped below the canopy as the UAV flew 15-20 m above ground level, which is consistent with responses to aerial predators [Karpanty and Wright, 2007]. No alarm calls occurred. A single screen shot image from live video of this last encounter is the only definitive imagery of a sifaka taken by the UAV, and thus no encounter rates were calculated and no direct comparisons made to the walking transects (Fig. 2). Sifaka group encounter rates from walking transects varied between forest fragments $(n=16$, mean $=0.30$ groups $/ \mathrm{km}$, range $=0.14-0.45$ groups $/ \mathrm{km})$.

Unfortunately, the UAV experienced several crashes due to battery failure, failure of the intelligent orientation control (IOC) and auto return-to-home software, and variable topography during the survey-testing phase. Many UAVs, including the one used in this study, have several fail-safe mechanisms that trigger when they lose controller contact or GPS signal. This triggers ATTI mode, in which the UAV retains altitude but not position, until it receives adequate GPS signal. When critical battery levels are met (Phantom 2: alert at 30\% battery life remaining, auto descent at 15\%), UAVs typically autonomously climb to a user-defined altitude and return to their launch point. In our case, the UAV reached $<20 \%$ battery life on our first survey when it was approximately $500 \mathrm{~m}$ from the launch point and attempted to return to the launch point. However, our UAV determined its altitude relative to the launch point and not its current point and then did not fly high enough to avoid trees on higher ground when returning to the launch point. UAV flights were arrested at this first site due to the dense canopy and hills and resumed at a site with less varied topography. On our subsequent surveys, given the lack of reliable barometric sensors and GPS in our UAV, we had to walk underneath the UAV to maintain a constant altitude for area calculations. Unfortunately, despite these precautions, the UAV dropped from the sky unexpectedly during a test flight at the second site and hit the hard ground from approximately $20 \mathrm{~m}$ AGL. It is likely that the first crash damaged the IOC system, as the flight pattern leading up to the crash was inconsistent with strong winds. The crash landing irreparably damaged the GoPro camera and gimbal mount. Subsequent flights were attempted using an iPhone (Apple, Cupertino, CA, USA), strapped to the UAV, but a third crash (tree strike over uneven terrain) put an end to field trials. Based on conversations with hobbyists, professional UAV pilots, and researchers using UAVs in their fieldwork [T. Reinsel, L. Dollar, S. Gilbert, J. McGee, E. Berge, pers. commun.], such results for beginner pilots are not uncommon. 


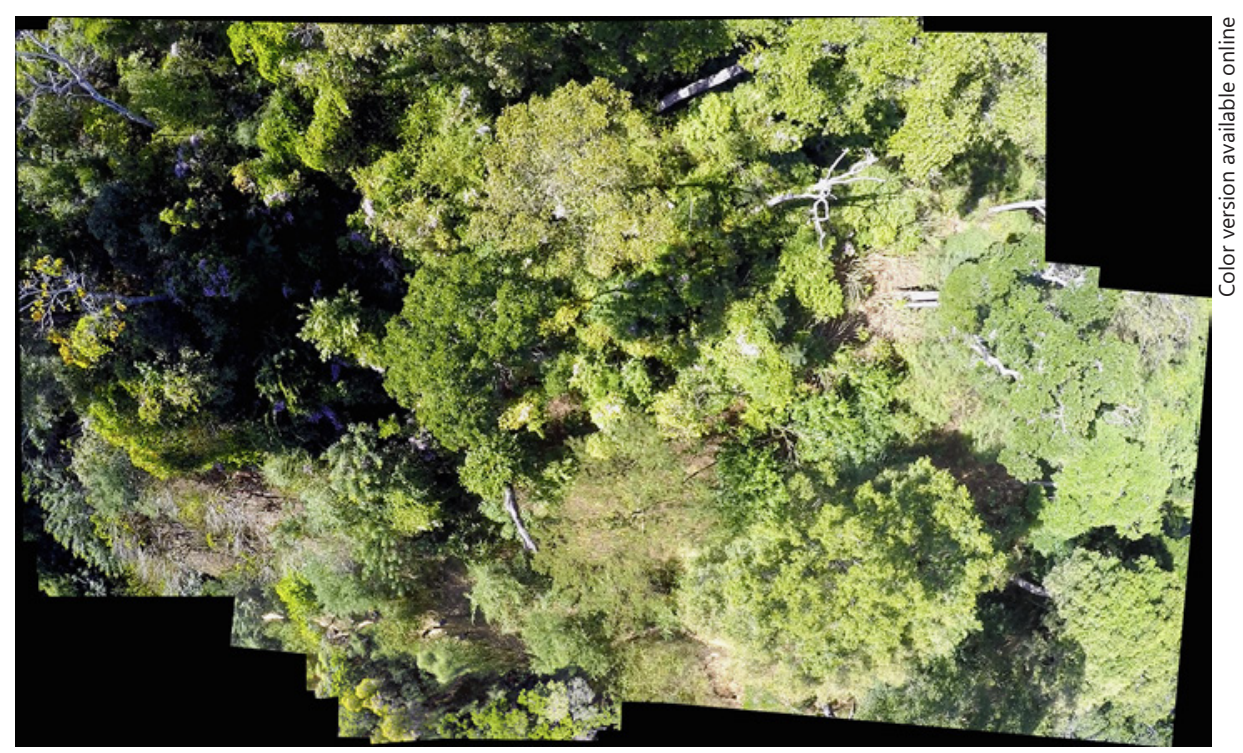

Fig. 3. Aerial imagery obtained from stitching together 36 still images from video in Image Composite Editor (Microsoft Corporation, Redmond, WA, USA). A GoPro Hero4 Silver took images from 15-20 m AGL.

Still images from video taken during successful flights were stitched together to create high-resolution images of the habitats on the flight path (2.6-3.0 MP/image in the stitch; Fig. 3). Human observers saw no lemurs during these image acquisition flights, nor were any lemurs found in post-flight analyses of imagery, as opposed to during the flights testing behavioural responses of known sifaka groups.

Because our refurbished consumer UAV model crashed on several occasions due to the failure of the barometric sensor and IOC and did not reliably detect sifakas, cost comparisons were conducted based on expected costs of a new, non-refurbished UAV (DJI Phantom 4 Pro) with a dual visible light (RGB) and forward-looking infrared (FLIR) thermal camera to ensure animal image capture (Table 1). While second-hand, refurbished models of this and other UAVs are available, the Phantom 4 Pro comes ready to fly and is supported by mission-planning software (DJI Pilot app), vision-positioning sensors, and a barometer to avoid obstacles and maintain constant altitude. High upfront costs for aerial surveys include the cost of the UAV, thermal camera, and additional flight permits (it should be noted that not all countries charge a fee for flight permits). In Madagascar, a UAV-based monitoring programme should break even with walking surveys at around $341 \mathrm{~km}$ of survey effort (Table 1).

\section{Discussion}

Our study demonstrates that it is possible to capture images of small-bodied, tree-dwelling sifakas and to collect high-resolution habitat imagery using a low-cost, ready-to-use UAV-mounted camera (Fig. 2). Prior to this study, the only published 
Table 1. Cost estimates (USD) for walking and possible UAV monitoring programmes for golden-crowned sifakas (Propithecus tattersalli) in Madagascar's Daraina region

\begin{tabular}{|c|c|c|c|c|}
\hline & Walking transects & & Improved UAV transects & \\
\hline \multirow[t]{7}{*}{ Supplies } & Range finder & 200 & - & - \\
\hline & $\begin{array}{l}\text { Data recording } \\
\text { (notebooks) }\end{array}$ & 100 & - & - \\
\hline & - & - & UAV (Phantom 4 Pro) ${ }^{1}$ & 1,500 \\
\hline & - & - & Thermal camera $(640 \times 512 \text { pixels })^{2,3}$ & 3,500 \\
\hline & - & - & 1-TB hard drive for image storage & 100 \\
\hline & - & - & $\begin{array}{l}\text { UAV extras (batteries, propellers, } \\
\text { case, insurance, etc.) }\end{array}$ & 1,000 \\
\hline & - & - & Solar battery charger ${ }^{4}$ & 1,000 \\
\hline \multirow[t]{2}{*}{ Permits } & Foreign researcher & 350 & Foreign researcher & 350 \\
\hline & - & - & UAV flight permit & 380 \\
\hline Set-up & Cut transects $^{5}$ & $15 / \mathrm{km}$ & - & - \\
\hline Local Malagasy field assistant & 5 assistants + food & $3 / \mathrm{km}$ & 1 assistant + food & $0.05 / \mathrm{km}$ \\
\hline \multirow[t]{2}{*}{ Data entry and processing } & $\begin{array}{l}90 \text { person-hours } \\
(272.2 \mathrm{~km}, 90 \mathrm{~h})\end{array}$ & $3.3 / \mathrm{km}$ & - & - \\
\hline & - & - & OBIA software (eCognition) $)^{6}$ & 0 \\
\hline \multicolumn{5}{|l|}{ Cost per distance ${ }^{7}$} \\
\hline $250 \mathrm{~km}$ & & 5,925 & & 7,843 \\
\hline $500 \mathrm{~km}$ & & 11,200 & & 7,855 \\
\hline $750 \mathrm{~km}$ & & 16,475 & & 7,868 \\
\hline $1,000 \mathrm{~km}$ & & 21,750 & & 7,880 \\
\hline
\end{tabular}

Estimates are based on 16 transects across five forest fragments (survey effort $=291.34 \mathrm{~km}$ ). Expected survey costs were then scaled for possible surveys with distances ranging from 250 to $1,000 \mathrm{~km}$. Principal investigator (PI) time commitment/salary are not included in cost estimates for any of the methods given high variance in those costs depending on experience level of the PI. UAV monitoring is cost effective after $341 \mathrm{~km}$ of survey effort. ${ }^{1} \mathrm{DJI}$, Shenzhen, China. ${ }^{2}$ FLIR Systems, Wilsonville, OR, USA. ${ }^{3}$ Pix4D recommends using a minimum $640 \times 480$ thermal sensor for mapping purposes. ${ }^{4}$ Goal Zero, Bluffdale, UT, USA. ${ }^{5}$ Each walking transect took one day to cut through forest $(27.2$ $\mathrm{km}$ of trails cut). Labour costs for local assistants are based on current market rates as set by non-profit research partner Fanamby. ${ }^{6}$ We assumed that OBIA (object-based imagery analysis) software (e.g., eCognition) was available at no charge through research universities. ${ }^{7}$ Estimates are calculated by taking the supplies, permits, set-up and local assistant and data processing costs and scaling by kilometre surveyed, based on costs in USD (2018 and not accounting for inflation). Expenses ubiquitous across methods (transport to and from site) are not included.

images of primates using a UAV have been of an orang-utan [Koh and Wich, 2012]. Most UAV population estimation or monitoring studies have been limited to large mammals [ >45 kg; Hodgson et al., 2013; Vermeulen et al., 2013; Moreland et al., 2015; Chrétien et al., 2016]. Studies of birds [Anatidae, $70-110 \mathrm{~cm}$ body length; Chabot and Bird, 2012; Anatidae, Phoenicopteridae, and Scolopacidae, 30-145 cm body length; Vas et al., 2015], sea otters [Enhydra lutris, 100-150 cm body length; Mitchell, 2015], chum salmon [Oncorhynchus keta, $60 \mathrm{~cm}$ body length; Kudo et al., 2012], loggerhead sea turtles [Caretta caretta, 70-102 cm body length; Schoefield et al., 2017], and now this study demonstrate the ability of commercially available UAVs to capture smaller 
animals. Additionally, this study demonstrates that UAVs passing by sifakas at a safe distance overhead (at least $10 \mathrm{~m}$ ) elicited minimal behavioural response; two of four groups exhibited no detectible response, one solitary individual descended in the canopy, and one group exhibited upward vigilance. Mulero-Pázmány et al. [2017] found that "lawn-mower" flight patterns by UAVs with electric motors over terrestrial mammals elicited some of the lowest wildlife behavioural responses. This study supports the findings of Mulero-Pázmány et al. [2017] and adds to a number of studies that have evaluated the varied behavioural effects of drones on wildlife [Vas et al., 2015; Bevans et al., 2018]. Obtained images may be used for up-to-date cover type or other habitat analyses and are an additional benefit to use of the UAV; including their value in a future cost-benefit analysis could show an even lower break-even point. Our current break-even cost estimate $(341 \mathrm{~km})$ is well within the range of walking transect effort required to obtain reliable data for this $[306.8 \mathrm{~km}$; Quéméré et al., 2010] and related sifaka species in similar forest types [359.68 km, Banks et al., 2007; 118 km, Kun-Rodrigues et al., 2014; 220.54 km, Salmona et al., 2014].

In addition to a steep learning curve, this study also demonstrates remaining challenges to using UAVs for monitoring primates, including permit restrictions, flight range and mobility, sensor reliability, return-to-home functions, battery power, ability to detect animals in a three-dimensional environment, environmental and cultural factors and unintended consequences of limiting observer presence in the primate habitat. While other studies have outlined important considerations for the use of lightweight UAVs for research in challenging conditions [Duffy et al., 2018], none have been done through the lens of primatologists, and we offer additional considerations over what has been stated in previous reviews in this list of considerations. We assess these factors below and then make recommendations for next steps based on our cost-benefit analysis.

\section{Permit Restrictions}

UAV permit restrictions must be considered for testing in the USA (Federal Aviation Authority; FAA) and for use abroad. As of August 29, 2016, the FAA's new Small Unmanned Aerial Systems Rule (Part 107) reduced qualification and training requirements for operators of small UAVs ( $<25 \mathrm{~kg}$ ); however, Part 107 certification or a Certificate of Waiver is still required for use of UAVs for research purposes. Laws are undergoing continuous review, and a full list of rules under Part 107 is on the FAA website [Federal Aviation Administration, 2019]. Additional requirements must be considered to operate in the primate host country. Unfortunately, many countries still do not have clear guidelines for what permits are required or how to obtain them. Hobbyists currently maintain an open source database of international UAV regulations online [Polat, 2017]. In Madagascar, the Civil Aviation Authority manages the UAV permit process at a cost of Ar 1,300,000 (approx. 380 USD) under Article 39 of the Interdepartmental Order between the Ministries of Transport and Budgeting and Finance (Arrêté Interministériel No. 18175-2013). It should be noted that not all countries charge a fee for these permits. US export restrictions must also be known prior to equipment purchase. In particular, export issues related to flight control and image-recording technology (e.g., thermal sensors; see "Animal detection in a threedimensional environment" below) should be checked with the manufacturer or your employer's export control office. 
Table 2. Popular low-cost, ready-to-use UAV models priced below 5,000 USD for the UAV body

\begin{tabular}{|c|c|c|c|c|c|c|}
\hline UAV model & Manufacturer & $\begin{array}{l}\text { MSRP, } \\
\text { USD }\end{array}$ & $\begin{array}{l}\text { Flight } \\
\text { time }^{1}, \text { min }\end{array}$ & $\begin{array}{l}\text { Inter- } \\
\text { changeable } \\
\text { camera }^{2}\end{array}$ & $\begin{array}{l}\text { Range }^{3} \text {, } \\
\mathrm{km}\end{array}$ & $\begin{array}{l}\text { Camera } \\
\text { resolution, MP }\end{array}$ \\
\hline Iris+ (gimbal not included $)^{4}$ & 3DRobotics & 600 & 16 & Yes & 1 & Not included \\
\hline Solo (with gimbal) ${ }^{4}$ & 3DRobotics & 1,400 & 25 & Yes & 0.8 & Not included \\
\hline Autel X-Star Premium ${ }^{4}$ & Autel Robotics & 799 & 25 & No & 2 & 12 \\
\hline Blade 350 QX3 $3^{4}$ & Horizon Hobby & 500 & 15 & Yes & 2.5 & 16 \\
\hline Blade Chroma with fixed GoPro mount ${ }^{4}$ & Horizon Hobby & 500 & 30 & Yes & 0.6 & Not included \\
\hline Blade Chroma with GoPro-ready gimbal ${ }^{4}$ & Horizon Hobby & 700 & 30 & Yes & 0.6 & Not included \\
\hline Blade Chroma with 1080 p camera ${ }^{4}$ & Horizon Hobby & 1,100 & 30 & No & 0.6 & 12 \\
\hline Blade Chroma with $4 \mathrm{~K}$ camera $^{4}$ & Horizon Hobby & 1,200 & 30 & No & 0.6 & 12 \\
\hline Inspire 1 & DJI & 1,999 & 27 & Yes & 5 & 12.4 \\
\hline Inspire 2 & DJI & 2,999 & 27 & Yes & 7 & Not included \\
\hline Inspire 2 Standard & DJI & 4,249 & 27 & Yes & 7 & 20 \\
\hline Mavic Air & DJI & 799 & 21 & No & 10 & 12 \\
\hline Mavic Pro & DJI & 1,000 & 27 & No & 7 & 12.3 \\
\hline Phantom $1^{4}$ & DJI & 499 & 15 & Yes & 1 & Variable \\
\hline Phantom $2^{4}$ & DJI & 599 & 25 & Yes & 1 & Variable \\
\hline Phantom 2 Vision $+^{4}$ & DJI & 899 & 25 & Yes & 2 & 14 \\
\hline Phantom 3 Standard & DJI & 699 & 25 & No & 1 & 12 \\
\hline Phantom 3 Advanced & DJI & 999 & 23 & No & 5 & 12 \\
\hline Phantom 3 Professional & DJI & 1,259 & 23 & No & 5 & 12 \\
\hline Phantom 4 & DJI & 1,199 & 28 & No & 5 & 12.4 \\
\hline Phantom 4 Pro & DJI & 1,499 & 30 & No & 7 & 20 \\
\hline Spark & DJI & 399 & 16 & No & 2 & 12 \\
\hline $\mathrm{Karma}^{4}$ & GoPro & 1,099 & 20 & Yes & 3 & Not included \\
\hline Hubsan $x 4$ Pro & Hubsan & 699 & 21 & Yes & 1 & 13 \\
\hline Next-Gen & Lily & 699 & 18 & No & 1 & 13 \\
\hline Bebop $^{4}$ & Parrot & 450 & 11 & No & 0.25 & 14 \\
\hline Bebop 2 & Parrot & 550 & 25 & No & 0.3 & 14 \\
\hline BEBOP 2 FPV & Parrot & 499 & 25 & No & 2 & 14 \\
\hline Disco FPV (fixed-wing UAV) ${ }^{4}$ & Parrot & 569 & 45 & No & 2 & 14 \\
\hline QR X350 PRO & Walkera & 339 & 25 & Yes & 2 & Not included \\
\hline QR X350 Premium & Walkera & 1,499 & 25 & Yes & 2 & 13 \\
\hline QR X900 & Walkera & 4,399 & 20 & Yes & 1 & Not included \\
\hline Scout X4 & Walkera & 739 & 25 & Yes & 2 & 12 \\
\hline Tali H500 & Walkera & 1,999 & 25 & Yes & 2 & 12 \\
\hline Voyager $3^{4}$ & Walkera & 1,999 & 25 & Yes & 2 & 16 \\
\hline Voyager 4 & Walkera & 3,099 & 20 & Yes & 1.5 & 16 \\
\hline Breeze & Yuneec & 499 & 12 & No & 0.1 & 13 \\
\hline Typhoon $\mathrm{G}^{4}$ & Yuneec & 900 & 25 & Yes & 0.4 & Not included \\
\hline Typhoon H & Yuneec & 1,299 & 25 & No & 1.6 & 12.4 \\
\hline Typhoon 4K RTF & Yuneec & 799 & 25 & No & 0.6 & 12 \\
\hline Typhoon Q500+ ${ }^{4}$ & Yuneec & 1,000 & 25 & Yes & 0.6 & 16 \\
\hline Typhoon Q500 4K & Yuneec & 1,200 & 25 & Yes & 0.4 & 12 \\
\hline Tornado H920 & Yuneec & 3,500 & 24 & Yes & 1.6 & 16 \\
\hline H520 & Yuneec & 1,999 & 28 & Yes & 1.6 & 12 \\
\hline
\end{tabular}

MSRP, manufacturer's suggested retail price. Only the Parrot Disco FPV fit these criteria for fixed-wing models. Most fixed-wing models require some assembly. Several models can support additional cameras, including thermal, though these may add considerable cost. All models include some flight-programming technology, and prices listed come directly from the manufacturer as of January 2019; table adapted from the Federal Aviation Administration [2019]. This list is not intended to be exhaustive. ${ }^{1}$ Flight time based on use of manufacturer-provided battery and calm weather conditions. ${ }^{2}$ Pix4Dmapper does not recommend using thermal cameras with a resolution below $640 \times 480$ pixels. ${ }^{3}$ Range is defined as the distance the UAV can travel from the launch point while maintaining contact with the pilot. For some UAVs, only the distance within which live stream video connections could be maintained were available. ${ }^{4}$ Model discontinued by manufacturer. 
Flight Range and Mobility

When considering which UAV to purchase, there are two basic UAV types that vary in their flight range and mobility. Fixed-wing UAVs have longer flight times (up to $1 \mathrm{~h}$ ) and can carry heavier payloads. However, they demand ample space for takeoff and landing, are less manoeuvrable, may resemble aerial predators, or are less available as low-cost, off-the-shelf models for purchase. Multi-rotor UAVs have the advantage of vertical take-off and landing and high manoeuvrability. They are lowcost and readily available online. Additionally, lemurs exhibited minimal antipredator behaviour in the presence of our quad-copter. Drawbacks include shorter battery life (20-30 $\mathrm{min})$ and reduced carrying capacity. A list of current low-cost, ready-touse UAVs as of January 2019 can be found in Table 2.

\section{Sensor Reliability and Homing Mechanisms}

Regardless of type, autopilot and altitude-sensing technology are critical to ensure the repeatability of flights and the calculation of survey and mapping areas. Flight-planning software now comes standard with many ready-to-use models. Unfortunately, this was not the case for our Phantom 2, making repeatable flight paths over uneven terrain difficult. Popular software for flight planning and even stitching imagery together include, but are not limited to, DroneDeploy, Pix4DMapper and Precision Flight, which offer a wide range of applications and services for no or minimal monthly fees. Additionally, obstacle-sensing technology is now largely available for multi-rotor models to further reduce flight risks in challenging terrain, though these should not be relied upon.

\section{Battery Power}

Most ready-to-use UAVs are battery powered. Remote controls, camera batteries and computers or tablets to programme flight paths also demand a regular supply of electricity. Our Yeti 400 solar generator with two 30-W panels could fully charge in a little over a day in ideal solar conditions, which then supplied enough energy for two UAV lithium ion batteries, allowing for two 25-min flights (batteries were stored and charged in a silver LiPo guard bag in the shade to avoid overheating). All other items (e.g., GoPro, controller) charged in $6 \mathrm{~h}$ under ideal conditions. Airlines allowed the generator and solar panels in checked baggage, while a limited number of lithium ion batteries (varies by airline) were allowed in carry on.

\section{Animal Detection in a Three-Dimensional Environment}

Most primates occupy three-dimensional space and may be obstructed from above by vegetation. Species that spend significant time resting in tree canopies (e.g., some sifakas [Propithecus spp.], howler monkeys [Alouatta spp.]) or those that inhabit grasslands (e.g., gelada [Theropithecus gelada] and savannah baboons [Papio spp.]) should be the focus of future studies. Strong pelage contrast with the surrounding environment is imperative for studies using visible light (RGB) cameras. Adding thermal infrared sensors improved sighting of white-tailed deer (Odocoileus virginia$n u s$ ) using object-based image analysis [Chrétien et al., 2016]. This approach detected up to $100 \%$ of deer with spatial resolution of $0.8 \mathrm{~cm} /$ pixel. Distinct signatures from combined image sources may even allow for automated image detection [Longmore et al., 2017]. Based on imagery obtained in this study, we would not recommend attempting direct primate surveys without the aid of thermal sensors, perhaps with the 
exception of species inhabiting short grassland environments, as leaves, branches, and shadows make even high-resolution imagery difficult to interpret. Thermal imagery is proving increasingly useful in wildlife detection in forested habitats [Gonzalez et al., 2016; Gooday et al., 2018; Witczuk et al., 2018]; however, this method still needs to be further tested on primates and in heavily forested systems. If detection by thermal imaging is proven useful for forest-dwelling primates, many species (like sifakas) could easily be distinguished from other animals by using concurrently collected RGB imagery.

While thermal imagery presents a promising path forward, limitations persist. Thermal cameras add to the already significant expense of UAVs. However, prices are dropping rapidly on UAVs and cameras (February 20, 2019: FLIR Vue Pro and Vue Pro R drone cameras 2,000-4,700 USD), second-hand devices are now readily available for even less than new devices, and the total costs of UAV and camera still remain less than the cost of many other remote tracking devices such as satellitebased tags when per animal costs are considered. The added weight of a second camera will reduce flight time duration. New dual-sensor imagers are emerging (FLIR Duo), though resolution remains low (thermal sensor resolution: $160 \times 120$ pixels). Thermal cameras remain limited in their ability to penetrate thick canopy cover, but future advances in remote, aerial survey work may enable more 3D density parameter estimates in programmes like DISTANCE [Thomas et al., 2010]. Thermal technology is strictly regulated, and import/export restrictions should be investigated early in the planning phase.

\section{Environmental and Cultural Factors}

Other factors that must be considered prior to conducting aerial surveys include environmental factors that may restrict UAV use. High winds may reduce realized flight distances per battery, blur imagery or prevent flights altogether. Objects in the canopy that may be confused for primates (e.g., large flowers, glare on tree trunks, termite mounds) should also be considered, though thermal sensors would reduce opportunities for misidentification, especially on cool, early mornings. Local perceptions of UAVs should also be considered, though in our experience, local people were very excited to witness flights and posed no objections to the UAV flying over their fields and homes.

\section{Unintended Consequences of Limiting Observer Presence in Primate Habitats}

The consequences of reducing foot patrols in favour of remote sensing techniques remain uncertain. While UAVs have been used in grassland antipoaching efforts [Bergenas et al., 2013; Mulero-Pázmány et al., 2014], this may be challenging in forest environments. While conducting ground transects, we found much evidence of poaching that would have been missed by UAV flights alone. Replacing walking transects with UAV surveys could also result in lost job opportunities for local people and thus loss of local support for conservation efforts. While local people could certainly be trained to use UAVs, there is a steep learning curve, and fewer people would be needed to conduct UAV surveys than to walk transects. In addition to the concerns above, the value of perspective from the ground alone (e.g., to detect hidden signs of illegal forest activity) means that UAV transects are unlikely to completely replace regular ground walking transect efforts entirely, rather, both are needed to differing degrees. 


\section{Future Directions}

Despite these challenges and uncertainties, UAVs continue to be cited as an avenue of future study for primatologists. UAVs are already being used to monitor other wildlife [Christie et al., 2016], to map land cover change [Rango et al., 2009] and to collect climate data [Bates et al., 2013]. For long-term monitoring over large remote areas, UAVs may be more cost-effective than walking surveys and will regularly collect high-resolution land cover data. UAV applications continue to expand across a range of disciplines; thus, UAV use will likely be in a future conservationist researcher's toolbox, and primatologists are best not getting left on the ground.

\section{Acknowledgement}

We thank Amidou, the Fanamby staff, and MICET for their assistance with data collection and logistics. We thank Earle Berge and Aylett Lipford for their helpful edits. Opinions, findings, conclusions or recommendations expressed are those of the authors and do not necessarily reflect the views of the NSF. We thank the Editor, Associate Editor and three anonymous reviewers for constructive edits that improved the manuscript.

\section{Statement of Ethics}

All research protocols in this manuscript have been read and approved by the Malagasy government and the Institutional Animal Care Committee of Virginia Tech (IACUC No. 15223). Research adhered to the American Society of Primatologists Principles for the Ethical Treatment of Non-Human Primates.

\section{Disclosure Statement}

The authors have no conflicts of interest to declare.

\section{Funding Sources}

Research was supported by NSF Grant No. DGE 1607310, Cleveland Metroparks Zoo, Cleveland Zoological Society, Stellar Aerobotics, Virginia Tech, International Primatological Society, Conservation International's Primate Action Fund and the American Society of Primatologists.

\section{References}

Altmann J (1974). Observational study of behavior: sampling methods. Behaviour 49: 227-267.

Andriaholinirina N, Baden A, Blanco M, Chikhi L, Cooke A, Davies N, et al. (2014). Propithecus tattersalli: The IUCN Red List of Threatened Species. Version 2014. http://www.iucnredlist.org/details/18352/0 (accessed December 18, 2016).

Banks MA, Ellis ER, Wright PC (2007). Global population size of a critically endangered lemur, Perrier's sifaka. Animal Conservation 10: 254-262.

Bates TS, Quinn PK, Johnson JE, Corless A, Brechtel FJ, Stalin SE, et al. (2013). Measurements of atmospheric aerosol vertical distributions above Svalbard, Norway, using unmanned aerial systems (UAS). Atmospheric Measurement Techniques 6: 2115-2120. 
Bergenas J, Stohl R, Georgieff A (2013). The other side of drones: saving wildlife in Africa and managing global crime. Conflict Trends 3: 3-9.

Bevans E, Whiting S, Tucker T, Guinea M, Raith A, Douglas R (2018). Measuring behavioral responses of sea turtles, saltwater crocodiles, and crested terns to drone disturbance to define ethical operating thresholds. PLoS One 13: e0194460.

Bonnin N, Van Andel A, Kerby J, Piel A, Pintea L, Wich S (2018). Assessment of chimpanzee nest detectability in drone-acquired images. Drones 2: 17.

Buckland ST, Plumptre AJ, Thomas L, Rexstad EA (2010). Design and analysis of line transect surveys for primates. International Journal of Primatology 31: 833-847.

Campbell G, Head J, Junker J, Nekaris KAI (2016). Primate abundance and distribution: background concepts and methods. In An Introduction to Primate Conservation (Wich SA, Marshall AJ, eds.), pp 79-110. New York, Oxford University Press.

Chabot D, Bird DM (2012). Evaluation of an off-the-shelf unmanned aircraft system for surveying flocks of geese. Waterbirds 35: 170-174.

Chrétien L-P, Théau J, Ménard P (2016). Visible and thermal infrared remote sensing for the detection of white-tailed deer using an unmanned aerial system. Wildlife Society Bulletin 40: 181-191.

Christie KS, Gilbert SL, Brown CL, Hatfield M, Hanson L (2016). Unmanned aircraft systems in wildlife research: current and future applications of a transformative technology. Frontiers in Ecology and the Environment 14: 241-251.

Duffy JP, Cunliffe AM, DeBell L, Sandbrook C, Wich SA, Shutler JD, et al. (2018). Location, location, location: considerations when using lightweight drones in challenging environments. Remote Sensing in Ecology and Conservation 4: 7-19.

Federal Aviation Administration (2019). Unmanned aircraft systems. https://www.faa.gov/uas/ (accessed December 15, 2016).

Gonzalez L, Montes G, Puig E, Johnson S, Mengersen K, Gaston K (2016). Unmanned aerial vehicles (UAVs) and artificial intelligence revolutionizing wildlife monitoring and conservation. Sensors 16: 97.

Gooday O, Key N, Goldstein S, Zawar-Reza P (2018). An assessment of thermal-image acquisition with an unmanned aerial vehicle (UAV) for direct counts of coastal marine mammals ashore. Journal of Unmanned Vehicle Systems 6: 100-108.

Grenzdorffer GJ (2013). UAS-based automatic bird count of a common gull colony. In Proceedings of the International Conference on Unmanned Aerial Vehicles in Geomatics. pp 169-174. Rostock, International Archives of the Photogrammetry, Remote Sensing and Spatial Information Sciences.

Hodgson A, Kelly N, Peel D (2013). Unmanned aerial vehicles (UAVs) for surveying marine fauna: a dugong case study. PLoS One 8: e79556.

Karpanty SM, Wright PC (2007). Predation on lemurs in the rainforest of Madagascar by multiple predator species: observations and experiments. In Primate Anti-Predator Strategies. Developments in Primatology: Progress and Prospects (Gursky SL, Nekaris KAI, eds.), pp 77-99. Boston, Springer.

Koh LP, Wich SA (2012). Dawn of drone ecology: low-cost autonomous aerial vehicles for conservation. Tropical Conservation Science 5: 121-132.

Kudo H, Koshino Y, Eto A, Ichimura M, Kaeriyama M (2012). Cost-effective accurate estimates of adult chum salmon, Oncorhynchus keta, abundance in a Japanese river using a radio-controlled helicopter. Fisheries Research 119-120: 94-98.

Kun-Rodrigues C, Salmona J, Besolo A, Rasolondraibe E, Rabarivola C, Marques TA, et al. (2014). New density estimates of a threatened sifaka species (Propithecus coquereli) in Ankarafantsika National Park. American Journal of Primatology 76: 515-528.

Laurance WF, Goosem M, Laurance SGW (2009). Impacts of roads and linear clearings on tropical forests. Trends in Ecology and Evolution 24: 659-669.

Lehman SM, Mayor M, Wright PC (2005). Ecogeographic size variations in sifakas: a test of the resource seasonality and resource quality hypotheses. American Journal of Physical Anthropology 126: 318328.

Li Y, Huang C, Ding P, Tang Z, Wood C (2007). Dramatic decline of François' langur Trachypithecus francoisi in Guangxi Province, China. Oryx 41: 38-43.

Linchant J, Lisein J, Semeki J, Lejeune P, Vermeulen C (2015). Are unmanned aircraft systems (UASs) the future of wildlife monitoring? A review of accomplishments and challenges. Mammal Review 45: 239-252.

Longmore SN, Collins RP, Pfeifer S, Fox SE, Mulero-Pázmány M, Bezombes F, et al. (2017). Adapting astronomical source detection software to help detect animals in thermal images obtained by unmanned aerial systems. International Journal of Remote Sensing 38: 2623-2638.

Matsuda I, Otani Y, Bernard H, Wong A, Tuuga A (2016). Primate survey in a Bornean flooded forest: evaluation of best approach and best timing. Mammal Study 41: 101-106.

Meyers DM (1993). The Behavioral Ecology of the Golden-Crowned Sifaka (Propithecus tattersalli). PhD Dissertation, Duke University. 
Mitchell S (2015). Researchers study sea otters with unmanned aircraft: UAF News Inf 2015. http://news. uaf.edu/researchers-study-sea-otters-unmanned-aircraft/ (accessed December 15, 2016).

Moreland EE, Cameron MF, Angliss RP, Boveng PL (2015). Evaluation of a ship-based unoccupied aircraft system (UAS) for surveys of spotted and ribbon seals in the Bering Sea pack ice. Journal of Unmanned Vehicle Systems 3: 114-122.

Mulero-Pázmány M, Jenni-Eiermann S, Strebel N, Sattler T, Negro JJ, Tablado Z (2017). Unmanned aircraft systems as a new source of disturbance for wildlife: a systematic review. PLoS One 12: e178448.

Mulero-Pázmány M, Stolper R, van Essen LD, Negro JJ, Sassen T (2014). Remotely piloted aircraft systems as a rhinoceros anti-poaching tool in Africa. PLoS One 9: e83873.

Paneque-Gálvez J, McCall M, Napoletano B, Wich S, Koh L (2014). Small drones for community-based forest monitoring: an assessment of their feasibility and potential in tropical areas. Forests 5: 14811507.

Peres CA (1999). General guidelines for standardizing line-transect surveys of tropical forest primates. Neotropical Primates 7: 11-16.

Polat A (2017). Drone laws for every country in the world (recreational use only). https://www.google. $\mathrm{com} / \mathrm{maps} / \mathrm{d} /$ viewer?mid = 1OkEtyCaGNjKhLeMr6L2IU975SP8 (accessed July 5, 2018).

Quéméré E, Champeau J, Besolo A, Rasolondraibe E, Rabarivola C, Crouau-Roy B, et al. (2010). Spatial variation in density and total size estimates in fragmented primate populations: the golden-crowned sifaka (Propithecus tattersalli). American Journal of Primatology 72: 72-80.

Quéméré E, Hibert F, Miquel C, Lhuillier E, Rasolondraibe E, Champeau J, et al. (2013). A DNA metabarcoding study of a primate dietary diversity and plasticity across its entire fragmented range. PLoS One 8: e58971.

Rango A, Laliberte A, Herrick JE, Winters C, Havstad K, Steele C, et al. (2009). Unmanned aerial vehiclebased remote sensing for rangeland assessment, monitoring, and management. Journal of Applied Remote Sensing 3: 033542.

Ravosa MJ, Meyers DM, Glander KE (1993). Relative growth of the limbs and trunk in sifakas: heterochronic, ecological and functional considerations. American Journal of Physical Anthropology 92: 499-520.

Salmona J, Rasolondraibe E, Jan F, Besolo A, Rakotoarisoa H, Meyler SV, et al. (2014). Conservation status and abundance of the crowned sifaka (Propithecus coronatus). Primate Conservation 28: 73-83.

Schoefield G, Katselidis K, Lilley M, Reina R, Hays G (2017). Detecting elusive aspects of wildlife ecology using UAVs: new insights on the mating dynamics and operational sex ratios of sea turtles. Functional Ecology 31: 2310-2319.

Thomas L, Buckland ST, Rexstad EA, Laake JL, Strindberg S, Hedley SL, et al. (2010). Distance software: design and analysis of distance sampling surveys for estimating population size. Journal of Applied Ecology 47: 5-14.

van Andel AC, Wich SA, Boesch C, Koh LP, Robbins MM, Kelly J, et al. (2015). Locating chimpanzee nests and identifying fruiting trees with an unmanned aerial vehicle. American Journal of Primatology 77 : 1122-1134.

Vas E, Lescroel A, Duriez O, Boguszewski G, Gremillet D (2015). Approaching birds with drones: first experiments and ethical guidelines. Biology Letters 11: 20140754.

Vermeulen C, Lejeune P, Lisein J, Sawadogo P, Bouché P (2013). Unmanned aerial survey of elephants. PLoS One 8: e54700.

Wich S, Dellatore D, Houghton M, Ardi R, Koh LP (2016). A preliminary assessment of using conservation drones for Sumatran orang-utan (Pongo abelii) distribution and density. Journal of Unmanned Vehicle Systems 4: 45-52.

Witczuk J, Pagacz S, Zmarz A, Cypel M (2018). Exploring the feasibility of unmanned aerial vehicles and thermal imaging for ungulate surveys in forests - preliminary results. International Journal of Remote Sensing 39: 5504-5521. 